\title{
Broadband Printed Modified Dipole for Personal Communication Systems
}

\author{
MARIO ROMERO-CASTRO ${ }^{1}$, MARIO REYES-AYALA ${ }^{1}$, EDGAR ALEJANDRO ANDRADE- \\ GONZALEZ $^{1}$, NICOLAS REYES-AYALA ${ }^{1}$, HILARIO TERRES-PEÑA ${ }^{2}$ \\ Department of Electronics ${ }^{1}$, Department of Energy ${ }^{2}$ \\ Metropolitan Autonomous University \\ San Pablo 180, Col. Reynosa Tamaulipas, Azcapotzalco, Zip Code 02200, Mexico City \\ MEXICO
}

\begin{abstract}
In this paper a modified printed dipole is proposed for mobile terminals operating in the first band of Personal Communication System (PCS) that is ranging from 800 to $900 \mathrm{MHz}$. One of the most important features of this kind of antenna is its wide bandwidth as required in the mentioned band. The modified design of the proposed antenna allows the user to move in any direction as is usual in mobile communications. The results of this article include an analytical design, simulations that have been performed numerically using a Finite Element Method (FEM) computational tool, structure optimization in order to maximize the antenna bandwidth and experimental measurements with the aim of spatial evaluating of electromagnetic radiated fields.
\end{abstract}

Key-Words: - Personal Communication Systems (PCS), modified dipole, broadband, printed antenna, Computational Electromagnetics (CEM), antenna gain, return losses.

Received: April 18, 2020. Revised: December 3, 2020. Accepted: December 19, 2020. Published: December 27, 2020.

\section{Introduction}

Printed antennas are used in modern wireless applications, because its features give us an adequate Electromagnetic Compatibility (EMC) and ease of installation and fabrication [1]. Therefore, this kind of antenna is used in terrestrial, maritime and aeronautical radiocommunication systems [2].

Rectangular, triangular o circular patch antennas are designed using transmission line, cavity o fullwave models, where the performance of the antenna is effective for a single carrier scheme and narrow band applications [5], [6], [11]. Transmission line model is based on a simplified LC resonant approximation, where the resonant frequency of the dominant mode is used to tune the carrier signal [3], [10], [12].

Modified printed antennas are used in multiband and broadband applications, where one or more elements are added in the structure. It is possible to include the new elements in the patch or in the ground plane (Defected Ground Structure, DGS) of the antenna [7], [8], [9]. DGS and modified antennas with slots or fractal edges are common in spread spectrum communication, where additional resonant frequencies are arranged in order to enlarge the bandwidth of the antenna [4],[16], or can be designed in several frequency bands as is used in Personal Communications Systems (PCS) [14], [17].

There are modern communication systems that use other sort of microstrip antennas, which use patches with different topologies, dipoles or bowties, for instance [13], [15]. Dipoles have a higher bandwidth in comparison with rectangular microstrip antennas and therefore are used in phased arrays, as well as millimeter wave imaging arrays [18]. In order to reduce radiation losses modified feeding networks have been proposed, where a truncated ground plane narrows down the length of the transmission line [19], [20].

Rare printed dipoles are been employed in primary-feed parabolic reflector antennas with a backward radiation feeder [21]. This kind of low-cost radiators are used as feeders located in the focus of the antenna, substituting conical or rectangular aperture feeders [22], [23]. Slotted quasi-Yagi antennas that are dipole-like feeders increase the bandwidth and can reduce the size of the ground plane [24], [25]. In this paper, a novel modified printed dipole is proposed and analyzed theoretical and experimentally, where the size of the ground plane is reduced. The quasi-Yagi structure presented in this paper modifies the antenna pattern with the 
aim of obtaining a wider main lobe beamwidth. In this case, the proposed antenna has been redesigned for a forward radiation, because this structure is not a feeder for any reflector antenna.

The modified dipole antenna was simulated and optimized using HFSS (High Frequency Simulation Software), that is a commercial software for electromagnetic structure analysis, which uses FEM algorithms [29].

\section{Modified Dipole Antenna}

Quasi-Yagi structure is based on modified dipole antennas and normally has the topology illustrated in Figure 1, where we can distinguish three main elements in a Printed Circuit Board (PCB): a dipole, a ground plane and a director/reflector. The size of the elements can modify the antenna pattern, because may reduce or enlarge the main lobe. In this work, that element is a director one, because the final application requires a wider main lobe.

The selection of the PCB is important in the performance of the antenna, because the thick $(H)$ and the dielectric constant $\left(\varepsilon_{\mathrm{r}}\right)$ of the substrate modifies the size of the frequency matching interval and the resonant frequency in the dominant mode, respectively.

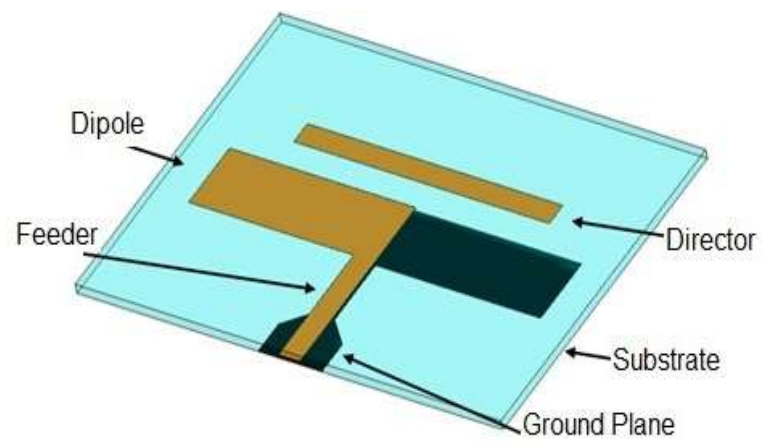

Fig. 1. Elements of a quasi-Yagi antenna.

The dipole of the quasi-Yagi structure is calculated according to the frequency of the carrier signal or central frequency of the antenna bandwidth. Taking in consideration the final application, the length of the director element will be greater or less than the dipole, if backward or forward radiation are preferred, respectively.

The size of the ground plane is computed in order to diminish the back-side lobe of the antenna or to decrease the size of the antenna. The model of the proposed antenna is shown in the Figure 2, where A and $\mathrm{B}$ are the width and length of the dipole respectively; $\mathrm{F}$ and $\mathrm{E}$ are the width and length of the director element, respectively; $\mathrm{P}$ and $\mathrm{G}$ are the width and length of the ground plane; $\mathrm{C}$ and $\mathrm{K}$ dimensions are calculated for the optimum interaction between the elements of the structure; and, the rest of the parameters (D and $\mathrm{J}$ ) are determined in order to get antenna matching.

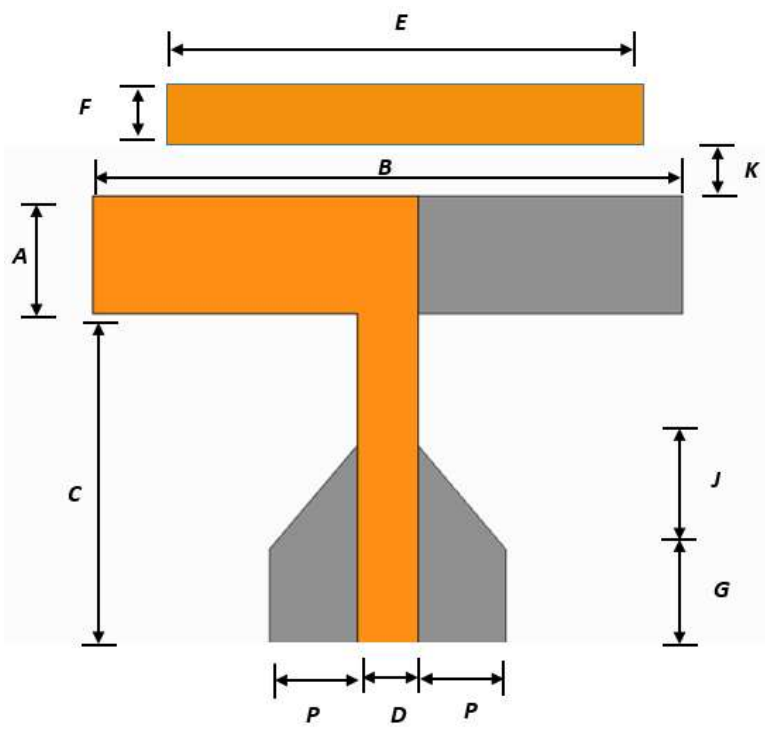

Fig. 2. Elements of a quasi-Yagi antenna.

The design procedure of the antenna is illustrated in Figure 3, where the first step is to define the main parameters of the PCB (dielectric constant, resonant frequency in the dominant mode and substrate thickness). In the second step, the width of the dipole is calculated as required to approximate an effective dielectric constant, that is equivalent to an inhomogeneous medium (air and substrate) for the flux lines of the electric field. In the third step the length of the feeder is calculated as the main parameter of the antenna impedance mismatch. The fourth step is dedicated to calculate the dipole length according to the frequency of the carrier signal. In the fifth step, the dimensions of the ground plane are completed; and, in the last step the distances between dipole elements are obtained. 


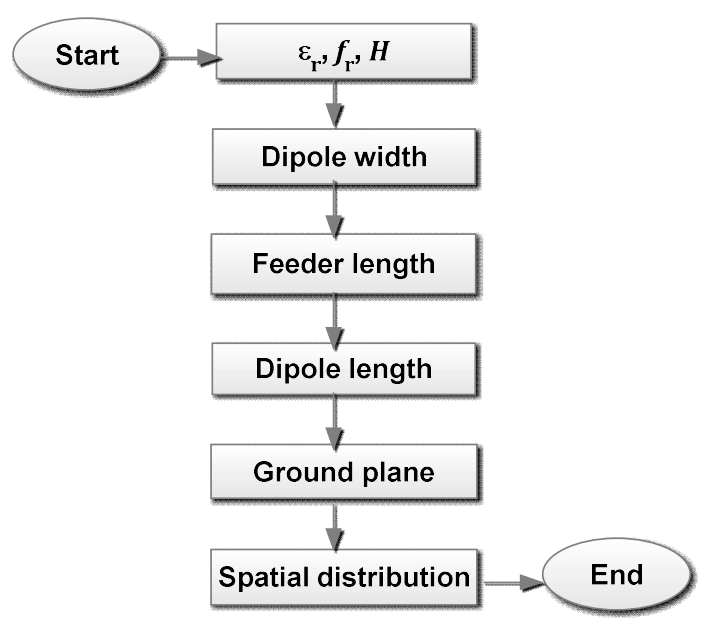

Fig. 3. Elements of a quasi-Yagi antenna.

\section{Antenna Model}

In this section the radiation of the dipole in free space is analyzed. Then, the structure of the dipole antenna is modified according to quasi-Yagi approach in order to manipulate the antenna pattern for a wider beamwidth.

The Electric Field Integral Equation (EFIE) in the cover of the dipole is determined by equation (1), where $\mathbf{G}^{e}\left(\mathbf{r} \mid \mathbf{r}^{\prime}\right)$ is an appropriate electric dyadic Green function; $\eta_{1}$ is the intrinsic impedance of the free-space, $\Omega$; and, $k_{1}$ is the wave-number of the free-space, $\mathrm{rad} / \mathrm{m}$.

$$
\mathbf{E}_{1}(\mathbf{r})=\frac{-j \eta_{1}}{k_{1}} \int_{S} \mathbf{G}^{e}\left(\mathbf{r} \mid \mathbf{r}^{\prime}\right) \cdot \mathbf{K}\left(\mathbf{r}^{\prime}\right) d \mathbf{S}^{\prime}
$$

The most useful procedure to solve the problem is to expand (1) in a series of a pole singularities [26], see equation (2), where $\omega_{q}$ is a complex natural frequency, $\mathrm{rad} / \mathrm{s} ; A_{q}$ is the amplitude of the $q$-th natural mode, $\mathrm{V}$; and, $\mathbf{k}_{q}(\mathbf{r})$ is the natural-mode current distribution associated with the $q$-th natural mode.

$$
\mathbf{K}\left(\mathbf{r}^{\prime}, \omega\right) \approx \sum_{q=1}^{Q} \frac{A_{q} \mathbf{k}_{q}(\mathbf{r})}{\left(\omega-\omega_{q}\right)}
$$

The resulting equation can not be solved directly, but full-wave models are able to simulate the structure, Method of Moments (MoM) for instance [26]. In that method, the use of a set of orthogonal functions are used to generate an impedance matrix. Other numerical techniques have been employed in order to get even a better approximation, where Finite Difference Time Domain (FDTD) and Finite Element Method (FEM) are two important CEM examples [27]-[28].

Then, there are no closed formulas to calculate the dimensions of the quasi-Yagi antennas, but it is possible to take into consideration several antennas designed in [18]-[25] and analyze their structures. In this paper, some formulas were employed to model an antenna for $800-900 \mathrm{MHz}$ cellular band.

Following the sequence of the design procedure shown in Figure 3, that was explained in the previous section, the modeling of the antenna is carried out.

The length of the director was changed in order to obtain a forward radiation, because in a land mobile application like cellular networks the vertical orientation of the terminal equipment is expected, see equation (3).

$$
A=\frac{v_{o}}{10 f_{r}} \sqrt{\frac{2}{\varepsilon_{\mathrm{r}}+1}}
$$

Where $f_{r}$ is the resonant frequency of the carrier signal, $\mathrm{Hz} ; v_{0}$ is the phase velocity of light in vacuum, $\mathrm{m} / \mathrm{s}$; and, $\varepsilon_{\mathrm{r}}$ is the dielectric constant of the substrate.

$$
\varepsilon_{r e f f}=\frac{\varepsilon_{r}+1}{2}+\frac{\varepsilon_{r}-1}{2}\left[1+12 \frac{H}{A}\right]^{-1 / 2}
$$

Where $\varepsilon_{\text {reff }}$ is the effective dielectric constant; and, $H$ is the thickness of the substrate, $\mathrm{m}$.

$$
B=\frac{\lambda}{2}=\frac{v_{o}}{f_{r} \sqrt{\varepsilon_{r e f f}}}
$$

Where $\lambda$ is the wavelength of the carrier signal in the substrate of the PCB, m.

$$
C=\frac{\lambda_{0}}{3 \sqrt{\varepsilon_{\text {reff }}}}
$$

Where $\lambda$ is the wavelength of the carrier signal in the vacuum of the PCB, $\mathrm{m}$.

$$
\begin{gathered}
D=\frac{C}{6} \\
F=0.9 D
\end{gathered}
$$




$$
\begin{gathered}
E=\frac{F}{0.08} \\
J=G=1.5 D \\
K=1.5 F
\end{gathered}
$$

The resulting dimensions of the antenna that is proposed in this work is presented in the Table 1.

\begin{tabular}{|c|c|c|}
\hline \multicolumn{2}{|c|}{ Parameter } & Value $(\mathrm{m})$ \\
\hline Dipole width & A & 0.029244091 \\
\hline Dipole length & B & 0.175688944 \\
\hline Feeder length & C & 0.058562981 \\
\hline Feeder width & D & 0.009760497 \\
\hline Director length & E & 0.10980559 \\
\hline Director width & F & 0.008784447 \\
\hline Ground plane length & G & 0.014640745 \\
\hline Ground plane junction & J & 0.014640745 \\
\hline Director-dipole distance & K & 0.010541337 \\
\hline Ground plane width increment & P & 0.009760497 \\
\hline
\end{tabular}

Table 1. Dimensions of the antenna

It is important to consider that the parameters of the PCB that was employed in the Table 1 were $H=$ $0.001544 \mathrm{~m}$ and $\varepsilon_{\mathrm{r}}=4.4$ (FR-4 substrate).

\section{Results}

The model of the quasi-Yagi antenna presented in the previous section was simulated and optimized in HFSS computational tool, that uses a FEM algorithm. This software automatically selects the mesh density with the intention to provide a good accuracy, moderate processing time and an enough memory limitation for computation.

The Figure 4 illustrates the model of the antenna in the simulation tool, where the radiation boundary of the structure is in a blue box filled with air. A standard $50 \Omega$ coaxial cable is used to feed the antenna using an electromagnetic wave-port. The elements of the antenna are built in copper patches with the thickness of $0.030 \mathrm{~mm}$. In that conditions, the center of phase of the antenna is centered in the dipole, where spherical waves are radiated to the radiation volume.

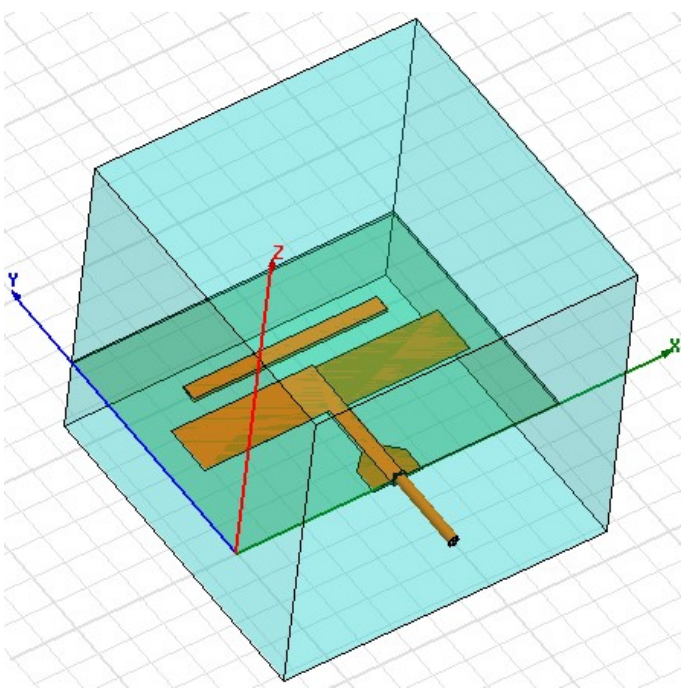

Fig. 4. Model of the quasi-Yagi antenna.

The behavior of the antenna in the frequency domain is evaluated using the return losses, that it is usually expressed with the $S_{11}(\mathrm{~dB})$ parameter in a logarithmic scale as is illustrated in the Figure 5. In that plot, there are two frequency intervals of the $S_{11}$ where this parameter is equal or less than $-10 \mathrm{~dB}$. Besides, it is easy to see that the marker number 3 $\left(m_{3}\right)$ is almost equal to $-10 \mathrm{~dB}$, causing the necessity of optimizing the structure.

It is possible to improve the performance of the antenna moving of the two resonant frequencies with the intention to obtain a single frequency interval. This optimization mechanism was followed for the antenna structure and its performance is shown in Figure 6.

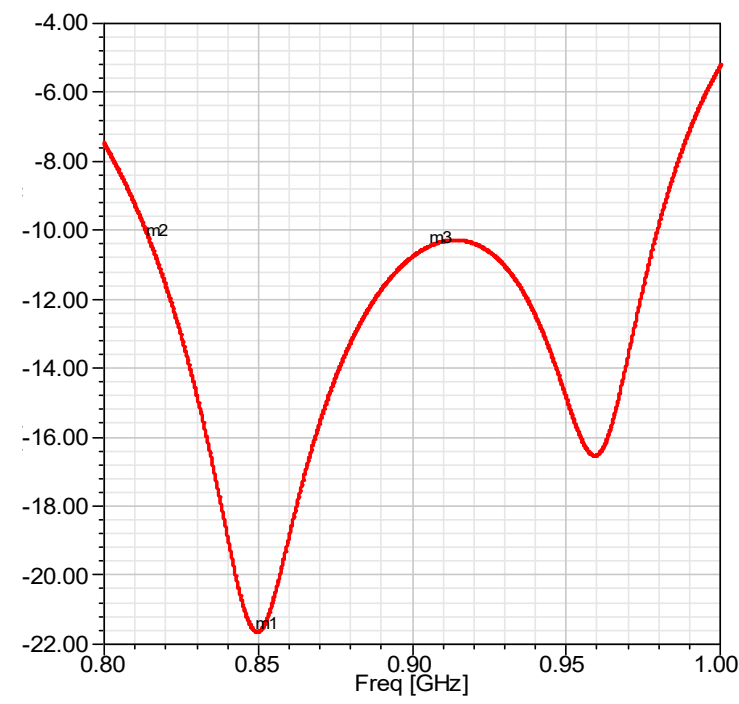

Fig. $5 S_{11}$ for the computed model of the antenna. 


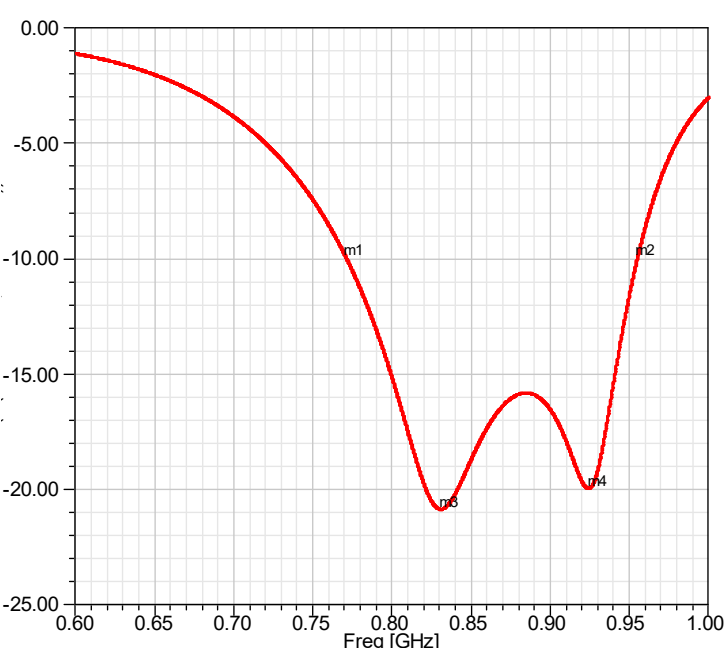

Fig. $6 S_{11}$ for the optimized model of the antenna.

The resulting bandwidth ( $B$ expressed as a percentage of the central frequency of the $800-900$ $\mathrm{MHz}$ band) of the optimized variation of the antenna is calculated in equation (10), where $f_{1}$ is the lower cut frequency, $\mathrm{Hz} ; f_{2}$ is the higher cut frequency, $\mathrm{Hz}$; and, $f_{\mathrm{r}}$ is the central frequency, $\mathrm{Hz}$.

$$
B=\left(\frac{f_{2-} f_{1}}{f_{r}}\right) \times(100 \%) \cong 20.65 \%
$$

The numerical results of the optimization process is presented in Table 2.

\begin{tabular}{|c|c|c|}
\hline \multicolumn{2}{|c|}{ Parameter } & Value (m) \\
\hline Dipole width & A & 0.030 \\
\hline Dipole length & B & 0.165 \\
\hline Feeder length & C & 0.055 \\
\hline Feeder width & D & 0.01 \\
\hline Director length & E & 0.12 \\
\hline Director width & F & 0.01 \\
\hline Ground plane length & G & 0.015 \\
\hline Ground plane junction & J & 0.01 \\
\hline Director-dipole distance & K & 0.012 \\
\hline Ground plane width increment & P & 0.01 \\
\hline
\end{tabular}

Table 2. Dimensions of the optimized variation of the antenna

The antenna patterns obtained after simulation and optimization are illustrated in the Figures 7 and 8, where the azimuthal angle is $0^{\circ}$ and $90^{\circ}$, respectively.

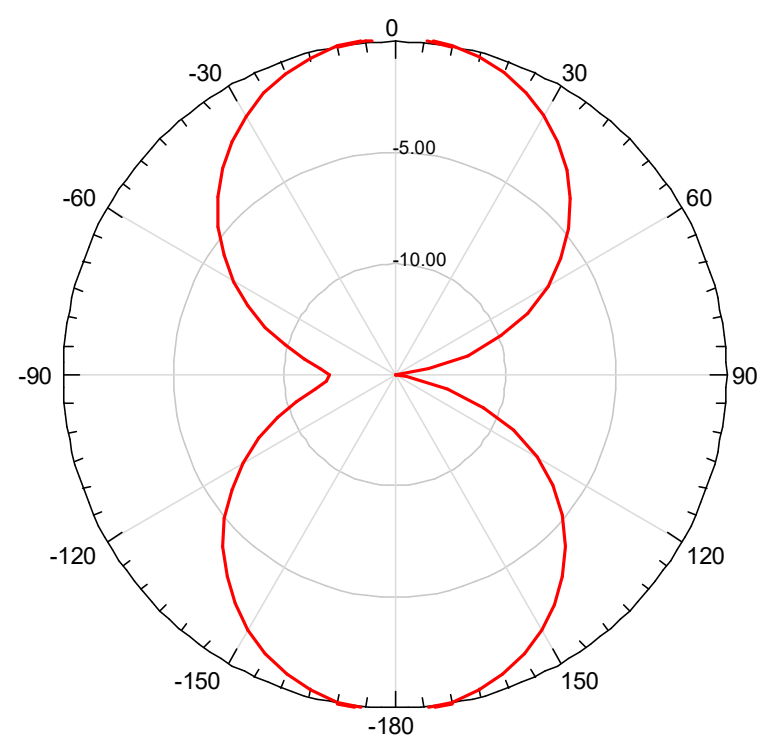

Fig. 7. Antenna pattern of the quasi-Yagi structure for $\phi=0^{\circ}$.

In these plots is clear that the antenna enlarges the main lobe in the antenna symmetry axis. This is a necessary condition to ensure a $30^{\circ}$ or higher in the elevation angle for urban coverage areas in land mobile radiocommunication systems.

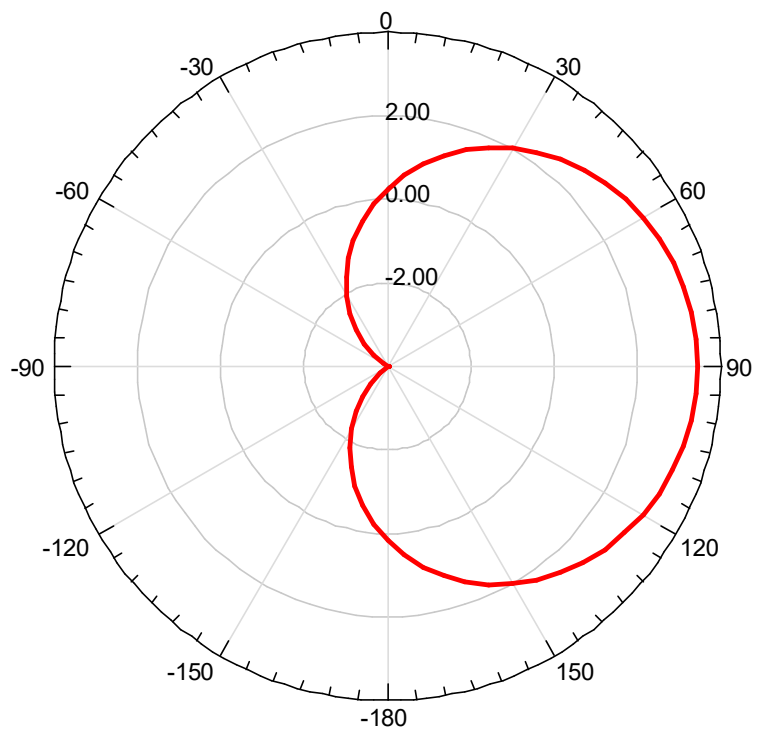

Fig. 8. Antenna pattern of the quasi-Yagi structure for $\phi=90^{\circ}$.

The optimized variation of the antenna was built as it is shown in top and bottom views in Figures 9 and 10 . 


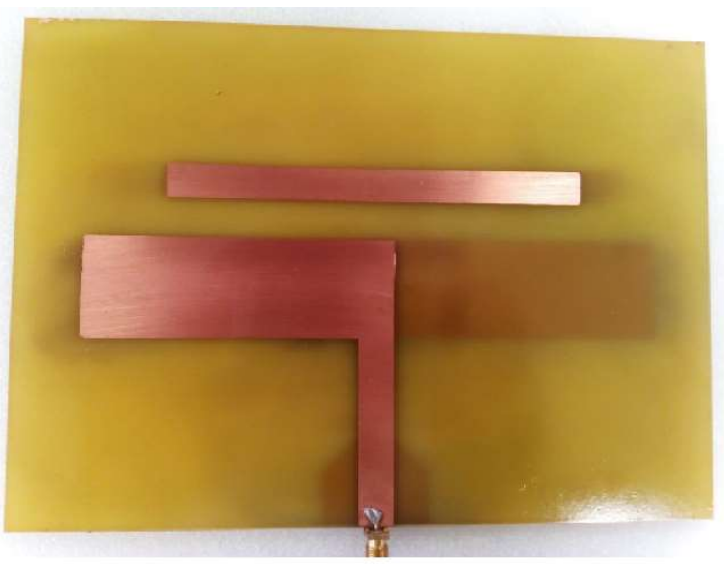

Fig. 9. Top view of the antenna.

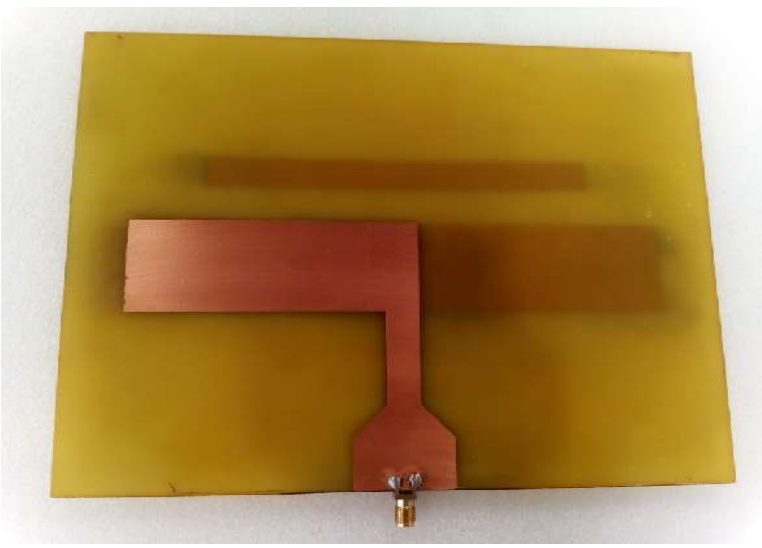

Fig. 10. Bottom view of the antenna.

The experimental evaluation of the antenna in the frequency domain was obtained using a Network Analyzer (NA) as is illustrated in Figure 11, where return losses are drawn in the vertical axis.

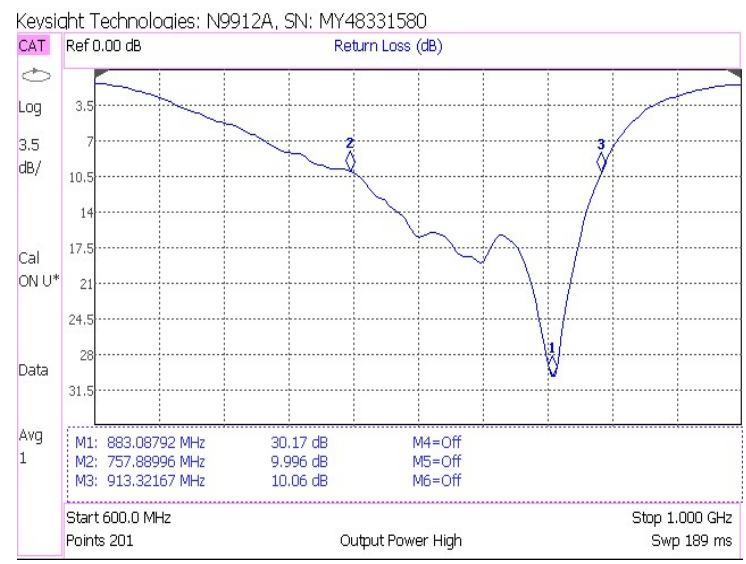

Fig. 11. Return losses of the antenna.

Finally, the experimental results of the spatial performance of the built antenna were obtained by

measuring the antenna patterns using a near field RF equipment and a Network Analyzer (NA). The RFxpert by EMSCAN is a compact scanner that calculates the far-field antenna pattern exploring in real-time the near field of the structure under test [30]. The microstrip antennas can be evaluated with this method because their geometry is flat and have a small size.

This experimental method does not require an anechoic chamber, because the power level of the sensing RF signals is very low for distances greater than $1 \mathrm{~m}$; but it is enough in the inductive radiated field of the antenna. In Figure 12 the near field configuration is shown.

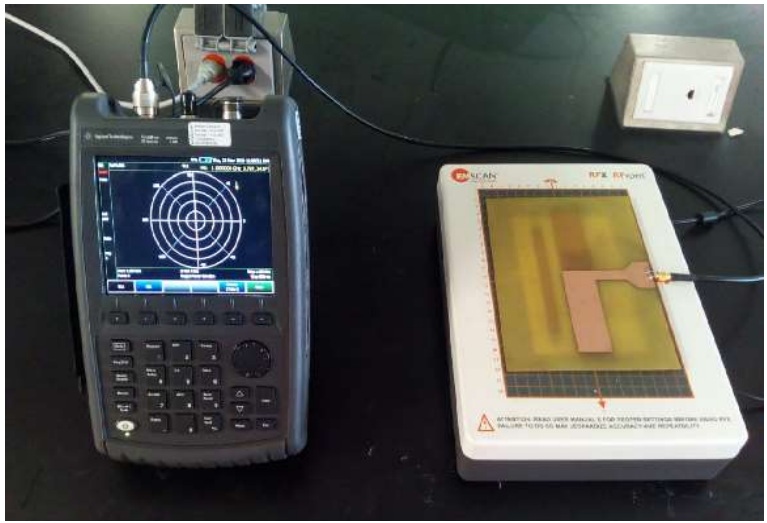

Fig. 12. Antenna pattern measurement.

In the Figure 13, the normalized antenna patterns measured using RFxpert for $0^{\circ}$ and $90^{\circ}$ in the most important elevation angles are shown.

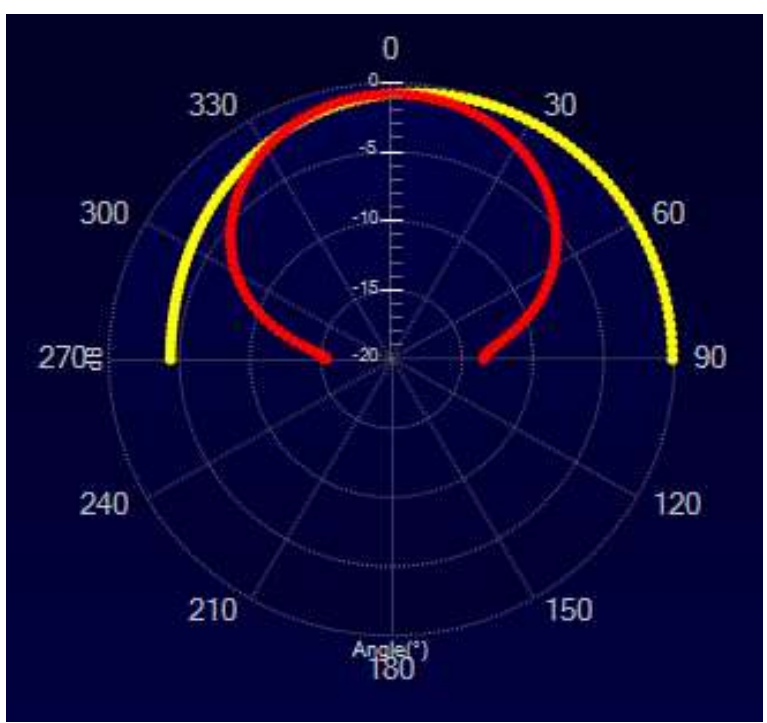

Fig. 13. Antenna patterns obtained experimentally. 
WSEAS TRANSACTIONS on COMMUNICATIONS

DOI: $10.37394 / 23204.2020 .19 .26$
Mario Romero-Castro, Mario Reyes-Ayala,

Edgar Alejandro Andrade-Gonzalez,

Nicolas Reyes-Ayala, Hilario Terres-Peña

\section{Conclusion}

A modified quasi-Yagi antenna for $800-900 \mathrm{MHz}$ band was carried out, which was designed using a set of empirical formulas. These mathematical expressions were obtained by analysis of some structures reported in the literature [18]-[28], where central frequencies ranging from $1 \mathrm{GHz}$ to $4 \mathrm{GHz}$, and their bandwidths are approximately equal to $20 \%$.

A commercial software package (HFSS) was used to simulate and optimize the tridimensional model of the antenna. The resulting model was built and measured in order to evaluate its performance in frequency domain and spatial radiation.

The bandwidth measured was $18.28 \%$ approximately, that is acceptable. The gain measured by near field interpolation was $4 \mathrm{~dB}$ approximately, that is similar in comparison with simulation results.

It is important to emphasize that the structure of the antenna was modified in order to enhance the main lobe of the antenna as is required in wireless communication in urban coverage areas. The radiation in the vertical axis is higher in comparison with backward variation of the reported antennas a lot of works.

Now, we are working with the aim of getting a better set of design formulas for the quasi-Yagi printed antennas, which could be more useful for a wider frequency intervals and more modern wireless applications.

\section{References:}

[1]. C. A. Balanis, Antenna Theory, 3rd Edition, New Jersey, John Wiley \& Sons, 2016.

[2]. J. L. Volakis, Antenna Engineering Handbook, McGraw-Hill, $5^{\text {th }}$ Edition, 2019.

[3]. D. M. Pozar, Microwave Engineering, 4th Edition, New Jersey, John Wiley \& Sons, 2012.

[4]. R. E. Munson, Conformal Microstrip Antennas and Microstrip Phased Arrays, IEEE Transactions on Antennas and Propagation, Vol. AP-22, No. 1, January, 1974, pp. 74 - 78.

[5]. J. Q. Howell, Microstrip Antennas, IEEE Transactions on Antennas and Propagation, Vol. AP-23, No. 1, January, 1975, pp. 90 - 93.

[6]. D. S. Chang, Analytical Theory of an Unloaded Rectangular Microstrip Patch, IEEE Transactions on Antennas and Propagation, Vol. AP-29, No. 1, January, 1981, pp. 54 - 62.

[7]. J. R. James, P. S. Hall, C. Wood, A. Henderson, Some Recent Developments in Microstrip
Antenna Design, IEEE Transactions on Antennas and Propagation, Vol. AP-29, No. 1, January, 1981, pp. 124 - 128.

[8]. W. F. Richards, Y. T. Lo, D. D. Harrison, “An Improved Theory for Microstrip Antennas and Applications, IEEE Transactions on Antennas and Propagation, Vol. AP-29, No. 1, January, 1981, pp. 38 - 46.

[9]. S. S. Hong, Y. T. Lo, Single-Element Rectangular Microstrip Antenna for DualFrequency Operation, Electronics Letters, Vol. 19, No. 8, August, 1983, pp. 298 - 300.

[10].H. Pues and A. Van de Capelle, Accurate Transmission-Line Model for the Rectangular Microstrip Antenna, IEE Proceedings, Vol. 131, No. 6, December, 1984, pp. $334-340$.

[11].E. Chang, S. A. Long, W. F. Richards, An Experimental Investigation of Electrically Thick Rectangular Microstrip Antennas, IEEE Transactions on Antennas and Propagation, Vol. 34, No. 6, June, 1986, pp. 767 - 772.

[12].D. M. Pozar, An Update on Microstrip Antenna Theory and Design Including Some Novel Feeding Techniques, IEEE Transactions on Antennas and Propagation Society Newsletter, Vol. 28, October, 1986, pp. 5 - 9.

[13]. D. Edward, D. Rees, A Broadband Printed Dipole with Integrated Balun, Microwave Journal, 1987, pp. 339 - 344.

[14]. J. S. Chen, K. L. Wong, A Single-Layer DualFrequency Rectangular Microstrip Patch Antenna using a Single Probe Feed, Microwave and Optical Technology Letters, Vol. 11, No. 2, February, 1996, pp. 83 - 84.

[15].K. W. Loi, S. Uysal, M. S. Leong, Design of a wideband microstrip bowtie patch antenna, IEE Proceedings - Microwaves Antennas and Propagation, Vol. 145, No. 2, April, 1998, pp. $137-140$.

[16]. Y. W. Jang, Broadband Cross-Shaped Microstrip-Fed Slot Antenna, Electronics Letters, Vol. 36, No. 25, December, 2000, pp. $2056-2057$.

[17]. Y. Tawk, K. Y. Kabalan, A. El-Hajj, C. G. Christodoulou, J. Constantine, A Simple Multibeam Printed Bowtie Antenna, IEEE Antennas and Wireless Propagation Letters, Vol.7, February, 2008, pp. $57-560$.

[18]. Y. Qian, W. R. Deal, N. Kaneda, T. Itoh, A Uniplanar Quasi-Yagi Antenna with Wide Bandwidth and Low Mutual Coupling Characteristics, 1999 IEEE AP-S International 
Symposium on Antennas and Propagation, July 1999, Vol. 2, pp. 924-927.

[19]. N. Kaneda, W. R. Deal, Y. Qian, R. Waterhouse, T. Itoh, A Broad-Band Planar Quasi-Yagi Antenna, IEEE Transactions on Antennas and Propagation, Vol. 50, No. 8, August, 2002, pp. $1158-1160$.

[20]. G. Zheng, A. A. Kishk, A. B. Yakovlev, A. W. Glisson, Simplified Feeding for a Modified Printed Yagi Antenna, 2003 IEEE Antennas and Propagation Society International Symposium, June 2003, pp. 934 - 937.

[21]. M. Qudrat-E-Maula, L. Shafai, Broadband Rare Radiating Printed Dipole Antenna, 2011 IEEE International Symposium on Antennas and Propagation, July 2011, pp. 255 - 258.

[22]. M. Qudrat-E-Maula, L. Shafai, Size Reduction of a Rear Radiating Microstrip Fed Printed Dipole Antenna, 2012 IEEE International Symposium on Antennas and Propagation, July 2012, pp. $1-2$.

[23]. M. Qudrat-E-Maula, L. Shafai, Low-Cost, Microstrip-Fed Printed Dipole for Prime Focus Reflector Feed, IEEE Transactions on Antennas and Propagation, Vol. 60, No. 11, November 2012, pp. $5428-5433$.

[24]. M. Qudrat-E-Maula, L. Shafai, Z. A. Pour, A Corrugated Printed Dipole Antenna With Equal Beamwidths, IEEE Transactions on Antennas and Propagation, Vol. 62, No. 3, March 2014, pp. $1469-1474$.

[25]. M. Qudrat-E-Maula, L. Shafai, A Dual Band Microstrip Dipole Antenna, $201416^{\text {th }}$ International Symposium on Antenna Technology and Applied Electromagnetics, July 2014, pp. $1-2$.

[26]. G. W. Hanson, D. P. Nyquist, The RCS of a Microstrip Dipole Deduced from an Expansion of Pole Singularities, IEEE Transactions on Antennas and Propagation, Vol. 41, No. 3, March 1993, pp. $376-379$.

[27]. C. Turkmen, Y. Bakirli, M. Secmen, Printed Quasi Yagi Antenna with Closely Spaced and Thick Directors for Triple ISM-Band/Wideband Applications at UHF, 2018 IEEE International Symposium on Antennas and Propagation \& USNC/URSI National Radio Science Meeting, July 2018, pp. $677-678$.

[28]. S. A. Alekseytsev, A. P. Gorbachev, The Novel Printed Dual-Band Quasi-Yagi Antenna With End-Fed Dipole-Like Driver, IEEE Transactions on Antennas and Propagation, Vol. 68, No. 5, May 2020, pp. 4088 - 4090.
[29]. www.ansys.com/products/electronics/ansyshfss.

[30]. https://www.inteli-cs.com/emscan/

\section{Creative Commons Attribution License 4.0 (Attribution 4.0 International, CC BY 4.0)}

This article is published under the terms of the Creative Commons Attribution License 4.0 https://creativecommons.org/licenses/by/4.0/deed.en US 